\title{
ФАКТОР ПОТЕРИ МОЩНОСТИ ФОТОЭЛЕКТРИЧЕСКИХ МОДУЛЕЙ ПРИ ИХ ВЗАИМНОМ ЗАТЕНЕНИИ И ОПТИМИЗАЦИЯ УГЛОВ НАКЛОНА И РАССТОЯНИЙ МЕЖДУ РЯДАМИ МОДУЛЕЙ
}

\author{
Д.А. Демин ${ }^{1,2}$, А.Н. Гаевская ${ }^{1}$, А.Ю. Гаевский ${ }^{1,2}$ \\ ${ }^{1}$ Национальный технический университет Украины «Киевский политехнический институт им. Игоря Сикорского», \\ 03056, пр. Победы, 37, г. Киев, Украина. \\ ${ }^{2}$ Институт возобновляемой энергетики НАН Украины, \\ 02094, ул. Гната Хоткевича, 20а, г. Киев, Украина.
}

Существенным фактором, влияющим на среднесуточную выработку электроэнергии фотоэлектрическими станциями $(\Phi Э С)$, является взаимное затенение соседними рядами фотомодулей (ФМ). Для уменьшения степени влияния взаимного затенения на выработку ФЭС необходимо решение задачи оптимизации межрядных расстояний и высоты рядов ФМ, т.е. их углов наклона. Несмотря на геометрический характер этой задачи, ее решение не является тривиальным, поскольку требуется учет изменения угла высоты Солнца, изменения интенсивности радиации на наклонной поверхности, а также вариации соотношения прямой и диффузной компонент радиации на протяжении светового дня и в течение всего календарного периода работы ФЭС. В данной работе для описания степени влияния частичного затенения на выходную мощность рядов ФМ введен фактор ослабления их мощности при затенении. Этот фактор определен на основе экспериментальных вольтамперных характеристик (ВАХ), снятых на разработанной нами установке для полевых измерений ВАХ в условиях нижнего затенения в случаях горизонтального и вертикального расположения модулей. Полученные зависимости фактора мощности ФМ от степени затенения использованы для вычисления предложенных нами карт среднесуточной выработки фотоэлектрической системы в координатах «плотность размещения рядов - угол наклона». Исходными данными, помимо фактора ослабления мощности, являются почасовые суммы прямой и диффузной радиации на горизонтальную поверхность для каждого месяиа периода работы ФЭС. Разработанный метод позволяет найти оптимальные конфигурачии рядов ФМ при решении двух типов задач: (1) обеспечения максимальной выработки при заданной установленой мощности ФЭС и (2) - получения максимальной выработки с единицы площади участка. Метод применим для любого сезонного периода работы ФЭС и любого региона, для которого имеются указанные выше радиачионные данные.Библ. 22, рис. 9.

Ключевые слова: фотоэлектрические станции, взаимное затенение рядов фотомодулей, оптимизация угла наклона, оптимизация расстояния между рядами фотомодулей, выработка электроэнергии.

\section{POWER LOSS FACTOR OF PV MODULES DUE TO MUTUAL SHADING AND OPTIMIZATION OF TILT ANGLES AND DISTANCE BETWEEN ROWS OF MODULES}

\author{
D. Diomin ${ }^{1,2}$, A. Gaevskaya1 ${ }^{1}$, A. Gaevskiii, ${ }^{1,2}$ \\ ${ }^{1}$ National Technical University of Ukraine «Igor Sikorsky Kyiv Polytechnic Institute», \\ 03056, 37 Peremohy Av., Kyiv, Ukraine. \\ ${ }^{2}$ Institute of Renewable Energy of the National Academy of Sciences of Ukraine, \\ 02094, 20A Hnata Khotkevycha St., Kyiv, Ukraine.
}

\begin{abstract}
A significant factor affecting on the average daily electricity output by photovoltaic $(P V)$ plants is the mutual shading by adjacent rows of PV modules. To reduce the mutual shading influence on the PV plant output one have to solve the problem of optimization of the inter-row distances and the height of the PV module arrays, i.e. the modules tilt angles. Despite the geometric nature of this problem, its solution is not trivial, since it's necessary to account the changing of the sun's height, the variations of the total irradiance on tilted surface and of the ratio of the direct and diffuse irradiance components during the daylight hours and during the entire calendar operation period of PV plant. In this paper, in order to describe the degree of influence of partial shading on the output power of PV rows the power attenuation factor due to shading has been introduced. This factor is determined on the basis of experimental current-voltage characteristics $(C V C)$, which were measured by the device developed in this work for testing of PV modules in field conditions with bottom shading in cases of horizontal and vertical arrangement of modules. The obtained dependences of the $P V$ power attenuation factor on the shading degree are used to calculate the average daily PV energy output maps in the coordinates "row placement density - tilt angle". As initial data, in addition to the power attenuation factor, are the hourly direct and diffuse insolation on a horizontal surface for each month of the PV plant operation. The developed method makes it possible to find the optimal configurations of the PV rows for two types of optimization problems: (1) ensuring maximum output at a given PV plant power and (2) obtaining maximum PV system output per unit area of the site. The method is applicable for any seasonal period of PV operation and for any region for which the above-mentioned insolation data are available. Ref. 22, fig. 9.
\end{abstract}

Keywords: PV plants, mutual shading of module rows, optimization of tilt angle, optimization of distance between module rows, $P V$ power output. 


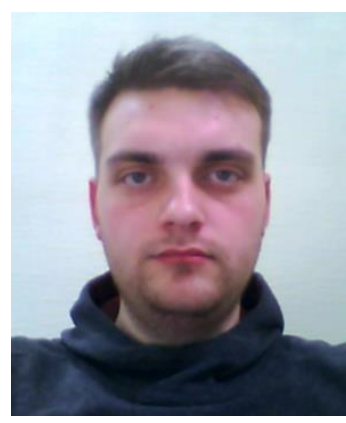

Д.А. Дёмин

D. Diomin

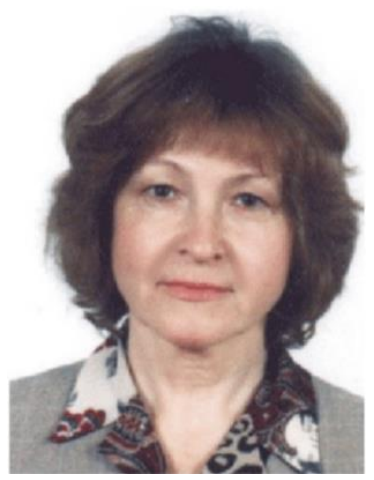

Сведения об авторе: старший преподаватель кафедры ВДЕ НТУУ «Киевский политехнический институт им. Игоря Сикорского».

Образование: НТУУ «Киевский политехнический институт им. Игоря Сикорского»

Научная сфера: электрические станции, компьютерное моделирование

Публикации: 19.

ORCID: 0000-0001-7760-6789

Контакты: +38 (067) 420-18-57

e-mail: ann.gaevskaya@gmail.com

А.Н. Гаевская

A. Gaevskaya

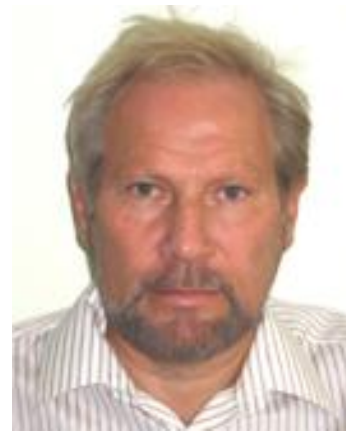

А.Ю. Гаевский

A. Gaevskii
Сведения об авторе: доктор физ.-мат. наук, профессор кафедри ВДЕ НТУУ «Киевский политехнический институт им. Игоря Сикорского».

Образование: НТУУ «Киевский политехнический институт им. Игоря Сикорского».

Научная сфера: возобновляемая энергетика, фотоэлектрические системы, компьютерное моделирование.

Публикации: 140.

ORCID: 0000-0001-6144-2441

Контакты: +38 (097) 570-46-43

e-mail: a.gaevskii@kpi.ua
Author information: Graduate student, Renewable Energy Institute of the NAS of Ukraine.

Education: NTUU Kyiv Polytechnic Institute.

Research area: renewable energy, designing and analytics of PV power plants.

Publications: 6 .

ORCID: 0000-0002-3350-6628

Contacts: +38 (066) 876-52-22

e-mail: mr.diomin@gmail.com

Autor information: Senior Teacher of the RES Department, NTUU «Igor Sikorsky Kyiv Polytechnic Institute»

Education: Kyiv Polytechnic Institute.

Research area: power plants, computer simulation.

Publications: 19.

ORCID: 0000-0001-7760-6789

Contacts: +38 (067) 420-18-57

e-mail: ann.gaevskaya@gmail.com

Autor information: Doctor of Phys. Math. Sci., Professor of the RES Department.

Education: NTUU «Igor Sikorsky Kyiv Polytechnic Institute».

Research area: renewable energy, PV systems, computer simulation.

Publications: 140

ORCID: 0000-0001-6144-2441

Contacts: +38 (097) 570-46-43

e-mail: a.gaevskii@kpi.ua
1. Введение. Величина электроэнергии, вырабатываемой фотоэлектрическими станциями (ФЭС) в значительной степени зависит от того, насколько оптимальной является конфигурация расположения рядов фотомодулей (ФМ). Для повышения уровня генерации ФЭС модули должны устанавливаться под определенными углами наклона и азимута. Кроме того, существенны межрядные расстояния и их соотношение с высотой рядов, а также размещение модулей внутри рядов: горизонтальное (альбомное) или вертикальное (портретное). Задаче оптимизации этих углов применительно к различным странам и регионам посвящены многочисленные работы [1-3]. В большинстве работ оптимальные наклон и азимут панелей выбираются из условия максимума суммы солнечной радиации, поступающей на единицу площади приемной поверхности за календарный период работы станции. На ФЭС большой мощности ряды модулей имеют, как правило, азимутальное направление приемной поверхности на юг и размещаются на свободном земельном участке, на котором отсутствуют крупные затеняющие объекты. Однако остается проблема частичного затенения соседними рядами модулей в часы, когда угол высоты Солнца не очень велик. При частичном затенении меняется расположение точки максимальной мощности на BAX, а также появляются дополнительные максимумы на кривой «мощность-напряжение нагрузки», что затрудняет работу алгоритмов МРРТ (Maximum Power Point Tracking) инверторов ФЭС. Но основным негативным следствием частичного затенения является падение выходной мощности затененных рядов ФМ [4-7]. 
Расчеты $[5,6]$ и эксперимент $[7,8]$ показывают, что фактор частичного затенения является существенным при проектировании ФЭС и оптимизации конфигурации рядов ФМ, а также для минимизации стоимости оборудования. Существенное влияние неоднородной освещенности на мощность ФЭС было подтверждено на многочисленных примерах при выполнении программы «1000 фотоэлектрических крыш» (1000-Roofs-PVProgramme), начатой в Германии в 1990 году [9].

На этапе проектирования ФЭС обязательно должен проводиться анализ влияния частичного затенения на суточную выработку электростанции. Такой анализ выполняется путем моделирования возможных изменений конфигурации тени на ФМ и соответственно выходной мощности станции. К настоящему времени разработаны различные аналитические и численные модели, учитывающие фактор затенения [5-11]. Настоящая работа ориентирована на подход, ранее предложенный авторами [8], который основан на определении экспериментальным путем фактора мощности затененных панелей $f(s)$ и на дальнейшем его применении для оптимизации межрядных расстояний и углов наклона солнечных панелей.

Определение фактора мощности в нашей работе основано на измерении вольтамперных характеристик (BAX) фотомодулей при различных степенях частичного затенения и на дальнейшем вычислении максимальной выходной мощности ФМ. С помощью специально разработанных экспериментальной установки и программного обеспечения выполнены измерения и обработка данных для различных условий затенения фотомодулей с различными вариантами размещения в рядах (альбомным или портретным). Измерения выполнялись на ФМ из монокристаллического и поликристаллического кремния.

2. Результаты измерений. В данной работе была реализована измерительная схема вольтамперной характеристики с помощью переменного сопротивления нагрузки (от 0 до 300 Ом), рассчитанная на фотомодули мощностью $80-150$ Вт и показанная на рис. 1. Экспериментальные данные относительно BAX поступали на систему сбора данных, построенную на основе микроконтроллеpa Atmel 328, имеющего ограничения по входному напряжению 5 В и разрешение 5 мВ. Напряжение на нагрузке $\mathrm{R}_{\text {load }}$ измерялось через делитель напряжения $\mathrm{R}_{1}-\mathrm{R}_{2}$, а ток в нагрузке контролировался с помощью токового шунта $R_{\text {shunt }}=0.23$ Ом. Одновременно с измерениями напряжений на резисторах измерялась освещенность с помощью модуля ВН1750 на фоторезисторе, что позволило ввести поправки на изменяющуюся солнечную радиацию в процессе измерений.

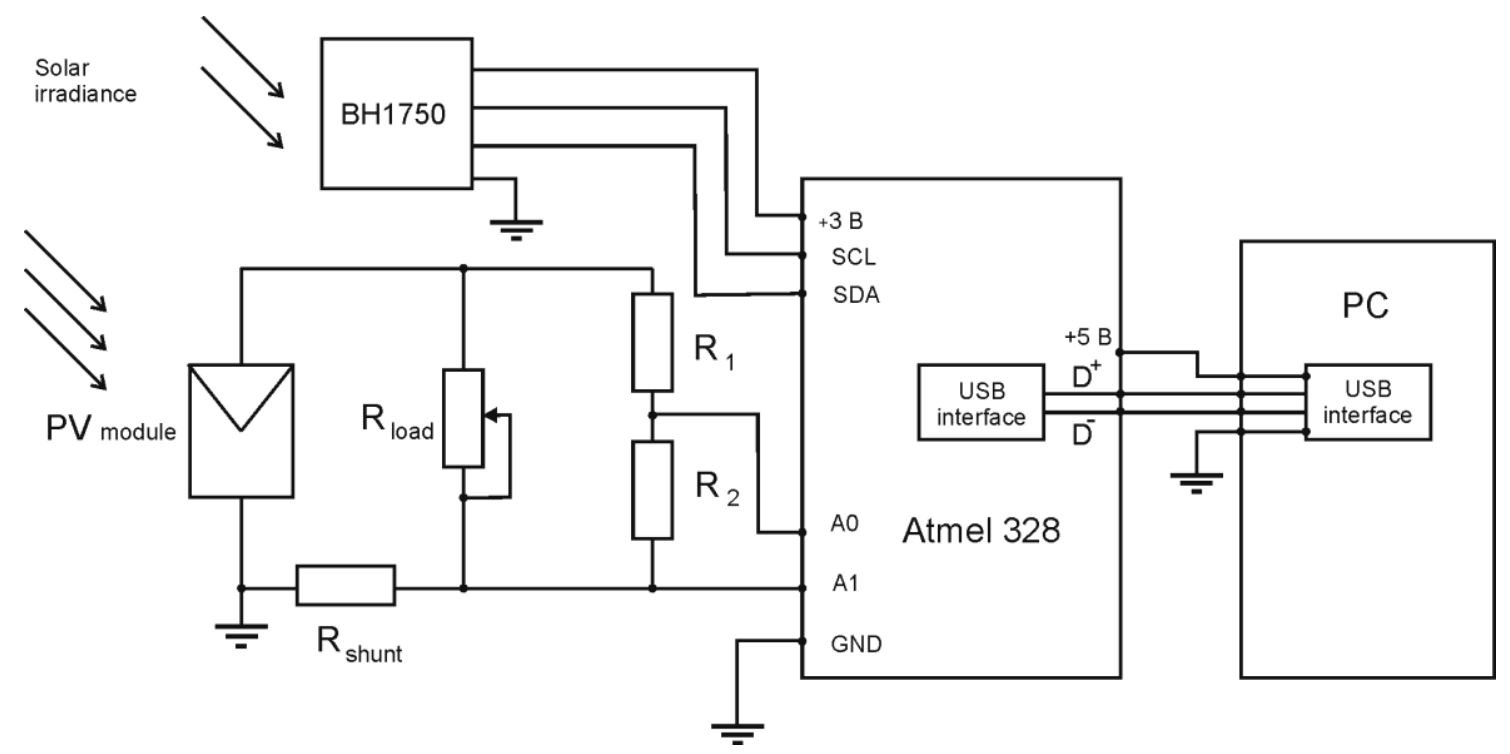

Рис.1. Схема измерения электрических характеристик ФМ.

Fig. 1. Scheme for measuring of electrical characteristics of PV modules.

Данные с АЦП микроконтроллера передавались через USB-интерфейс в ПК и записывались в файл. Дальнейшая обработка и аппроксимация BAX выполнялись с помощью специализированных программ в пакете MATLAB. В ходе экспе- риментов была снята BAX фотомодулей из монокристаллического и поликристаллического кремния при различных степенях затенения и определены характеристики основных режимов работы ФМ: максимума мощности (ММ), холо- 
стого хода $(\mathrm{XX)}$ и короткого замыкания (КЗ).

3. Моделирование ВАX фотомодулей в условиях частичного затенения. В данной работе исследовано взаимное затенение рядами солнечных панелей, которое чаще всего наблюдается в утренние и вечерние часы работы ФЭС, а также влияние затенения на параметры ФМ, характеризующие электрические потери. Тень начинает появляться в нижней части ФМ и распространяться вверх по мере уменьшения высоты Солнца, что отвечает постепенному затенению рядов последовательно соединенных фотоэлектрических ячеек. Результаты экспериментов, полученные для подобного типа затенения, показаны на рис. 2. Кривые с меньшими значениями тока КЗ соответствуют возрастающей площади частичного затенения.
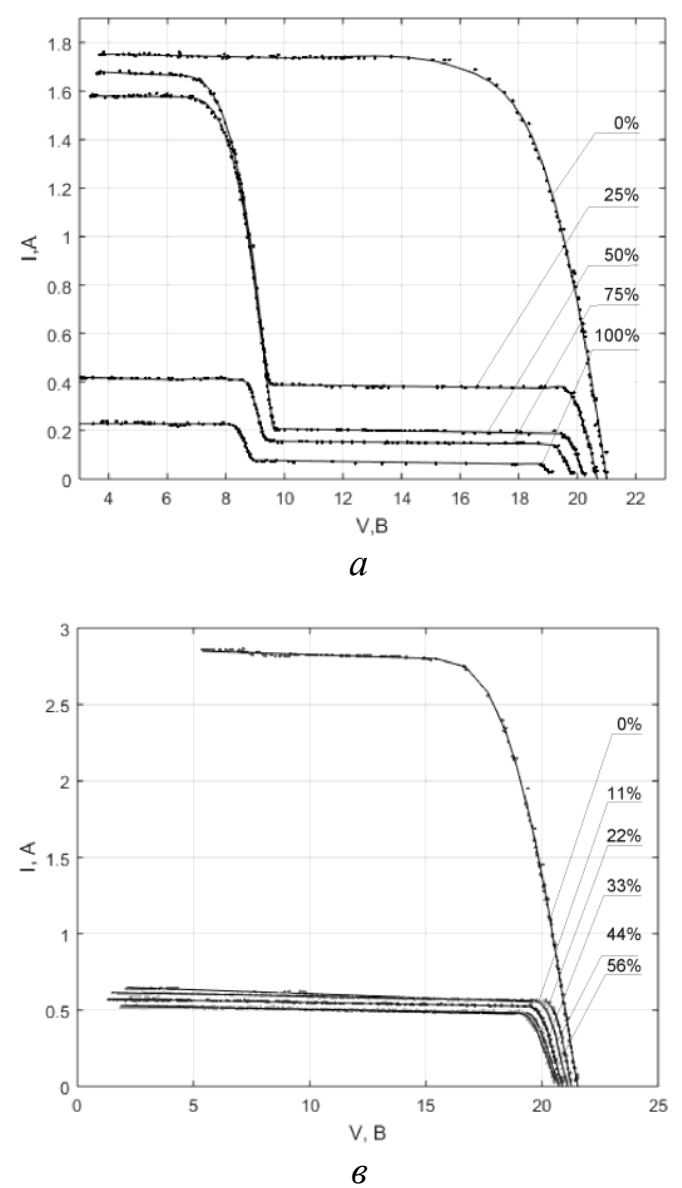

Если модуль расположен горизонтально (альбомная ориентация), то при частичном затенении нижней части модуля падает фотогенерация одной из серий последовательно соединенных фотоэлектрических ячеек. В результате ВАХ $I(V)$ имеет многоступенчатый характер (рис. 2a) и соответственно зависимость мощности от напряжения на нагрузке $P(V)$ характеризуется несколькими максимумами (рис. 2б). Если же модуль расположенном вертикально (портретная ориентация), то при нижнем затенении происходит одновременное падение фотогенерации всех серий последовательно соединенных ячеек. При этом кривая $I(V)$ лишь смещается по току без изменения формы (рис. 2в), а кривая $P(V)$ не распадается на несколько максимумов (рис. 2г).

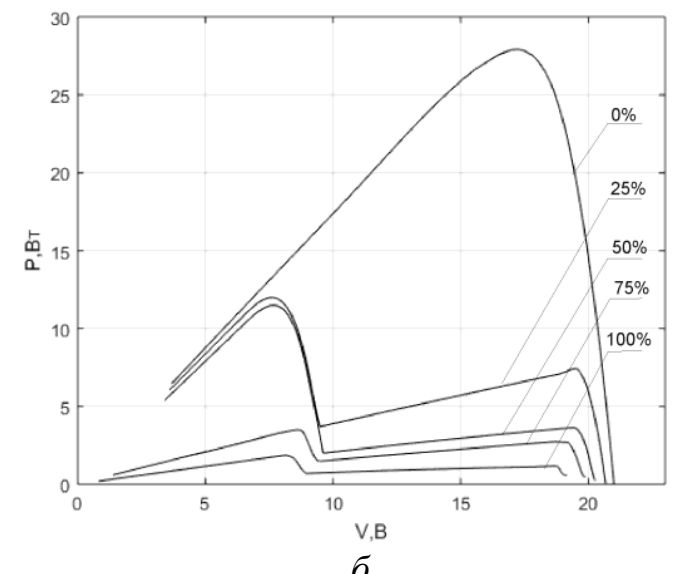

6

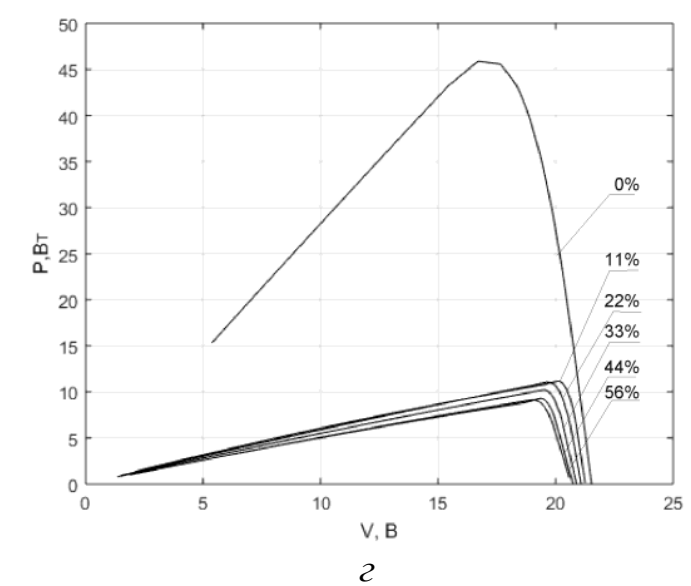

Рис. 2. BAX (a, в) и зависимости мощности от напряжения нагрузки (б, г): a, 6 - nоли-Si модуль $K v a z a r ~ K V-100 W c$ aльбомной ориентачией; в,г-моно-Si модуль SunRise SR 100W с портретной ориентацией.

Fig. 2. CVC (a, B) and the dependence of power on the load voltage (б, г): $a$, b - poly-Si module Kvazar KV-100W with landscape orientation; c, $d$-Mono-Si module SunRise SR $100 W$ with portrait orientation.

Для корректного определения параметров ФМ необходимым этапом является предварительная обработка результатов измерений, которая заключается в сортировке данных и их аппроксимации с помощью модельных кривых.
Функции, представляющие эти кривые, позволяют найти пары значений $(I, V)$ в экспериментально недостижимых точках к.з. и х.х. К настоящему времени известен ряд работ, в которых выполняется моделирование ВАХ ФМ с помощью раз- 
личных классов функций (экспоненциальных, как в формуле Шокли [12-14], функции Ламберта [15-17], нейронных сетей [18] и др.). В данной работе при моделировании ВАХ была применена кусочно-полиномиальная аппроксимация. Согласно работе [19] аппроксимирующая функция задавалась на четырех характерных интервалах BAX: в окрестностях К3, XX и максимума мощности. Коэффициенты при степенях аппроксимирующих полиномов определялись методом наименьших квадратов и удовлетворяли условиям непрерывности аппроксимант и их производных. В процессе подгонки модельной кривой под экспериментальные данные оптимизировалось также расположение точек сшивания аппроксимирующих кривых.

Следующий этап после аппроксимации экспериментально полученной ВАХ заключается в определении («экстракции») основных параметров ФМ, описывающих поведение модуля в рамках эквивалентной схемы замещения (см. обзор $[13,20])$. Для нахождения этих параметров необходимо решать систему нелинейных уравнений, как в задаче непосредственного определения параметров, так и в задаче подгонки параметров под эксперимент путем нелинейной оптимизации. Как известно, при решении таких систем требуется задание начальных значений параметров, от которых в определяющей степени зависит результат последующего итерационного процесca. Для пяти- и семипараметрических моделей однодиодной и двухдиодной схем замещения адекватный результат можно получить, если удачно выбраны начальные значения [6, 13]. Опыт показывает, что лишь небольшие изменения стартовых значений приводят к нефизичным и непредсказуемым результатам. Это особенно характерно для экстракции параметров на основе полевых измерений ФМ. Определение стартовых значений в этих случаях представляет собой отдельную задачу, во многом зависящую от навыков оператора. Поэтому важным представляется построение устойчивого алгоритма определения характеристик ФМ, который можно применять, когда заранее не известны параметры схем замещения. Разработке такого алгоритма определения параметров и применению его к экспериментальным данным ФМ посвящена работа [21]. Метод экстракции, развитый в этой работе, не требует начальных параметров и является устойчивым при выполнении итерационных вычислений.

Для однодиодной схемы замещения речь идет о вычислении набора параметров $\theta=\left\{I_{p h}, R_{s}, R_{p}, I_{0}, A\right\}$, где $I_{p h}-$ ток фотогенерации, $R_{s}$ и $R_{p}$ - последовательное и параллельное (шунтирующее) сопротивления потерь, $I_{0}-$ обратный ток насыщения диода, описывающего рn-переход, $A$ - коэффициент неидеальности диода, значения которого лежат в интервале от 1 до 2. Алгоритм решения системы уравнений для набора $\theta$ [21] основан на аналитическом разложении нелинейных уравнений для основных режимов работы ФМ по малым параметрам, являющимся комбинациями величин из набора $\theta$. Применение этого метода к экспериментальным данным, приведенным на рисунках 2, позволяет найти, например, сопротивление $R_{s}$, отвечающее за основные электрические потери в ФМ (потери в объемном слое полупроводников и в системе контактов). Соответствующие кривые, показывающие зависимость потерь от степени затенения, приведены на рис. 3.
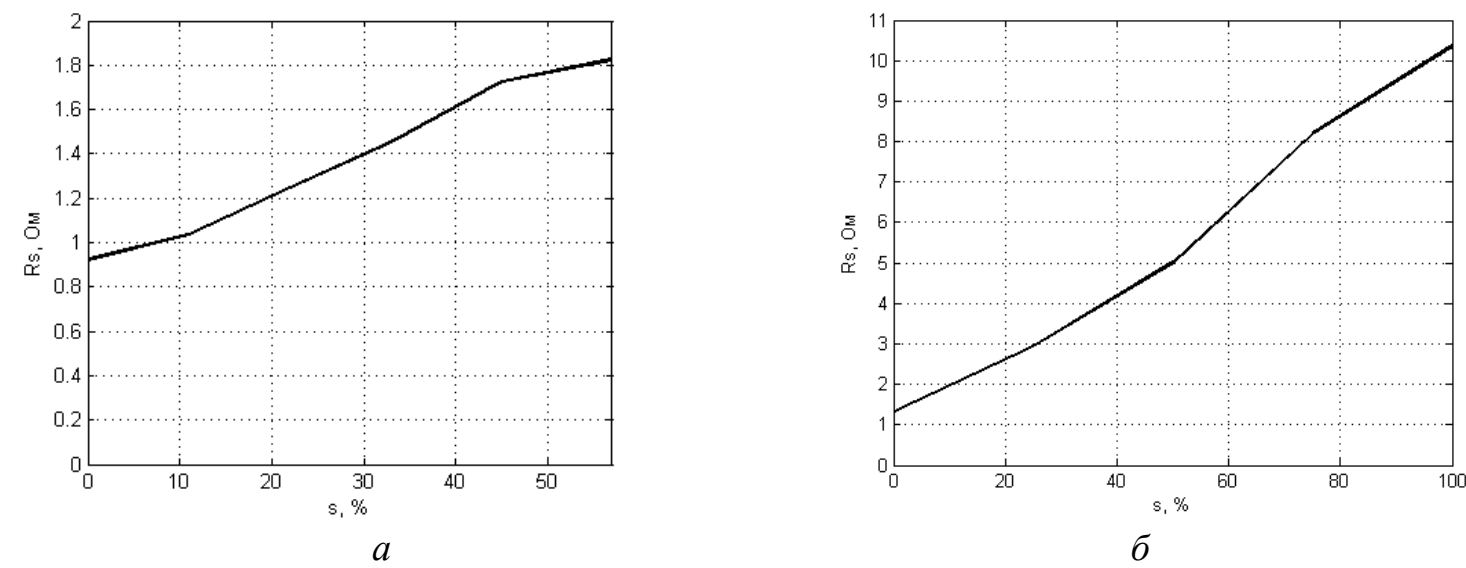

Рис. 3. Зависимости последовательного сопротивления потерь $\mathbf{R}_{\mathrm{s}}$ от относительной площади нижнего затенения s: $a-$ портретная ориентация моно-Si модуля SunRise SR 100W; б - альбомная ориентация поли-Si модуля Kvazar KV-100W.

Fig. 3. Dependences of the series loss resistance Rs on the relative area of the lower shading s: a - portrait orientation of the mono-Si module SunRise SR 100W; b - landscape orientation of the poly-Si module Kvazar KV-100W. 
Последовательное сопротивление $R_{s}$ наиболее сильно влияет на поведение ВАХ модуля в окрестности максимума мощности и вблизи холостого хода. Из графиков на рис. 3 видно, что в отсутствие затенения $R_{s}$ меньше у ФМ из монокристаллического кремния. С появлением частичного затенения и увеличением его до полного затенения сопротивление потерь существенно растет: $R_{s}$ возрастает примерно в два раза для портретной ориентации и примерно в 10 раз - для альбомной ориентации, если оценивать это сопротивление в окрестности точки холостого хода.

4. Потери мощности при затенении ФМ. Влияние взаимного затенения на мощность ФМ будем характеризовать коэффициентом потерь, который равен

$$
K_{\text {loss }}\left(s, I_{s}, I_{t 0}\right)=\frac{P\left(s=0, I_{t 0}\right)-P\left(s, I_{s}, I_{t 0}\right)}{P\left(s=0, I_{t 0}\right)},
$$

где $P\left(s, I_{s}, I_{t 0}\right)$ - электрическая мощность в нагрузке при степени нижнего затенения $s$, $I_{s}$ и $I_{t 0}-$ интенсивности радиации в тени и на освещенной наклонной поверхности; $P\left(s=0, I_{t 0}\right)$ - мощность в нагрузке в отсутствие тени. Степень затенения определяется нами [8] как отношение площади затененной части ряда к полной площади ряда (рис.4):

$$
s=\frac{S_{\text {shad }}}{S_{0}}=\frac{l \cos \beta}{L},
$$

где $l$ - высота рамки, обрамляющей солнечную панель, $\beta$ - угол наклона панели, $L-$ период регулярного расположения панелей.

Введем также фактор потери мощности затененной панелью [8], равный

$$
f\left(s, I_{s}, I_{T}\right)=1-K_{\text {loss }}=\frac{P\left(s, I_{s}, I_{T}\right)}{P\left(s=0, I_{T}\right)} .
$$

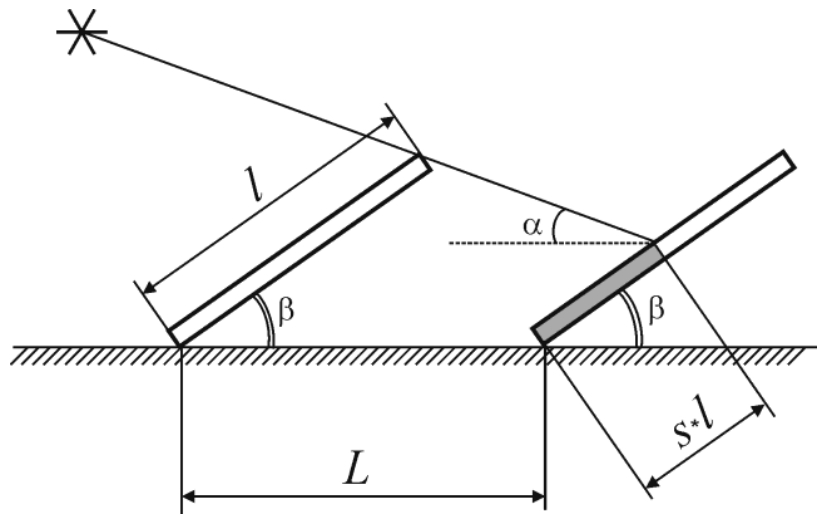

Рис. 4. Геометрия взаимного затенения рядами солнечных панелей.

Fig. 4. Self-shading geometry of solar panels rows.

Освещенность в области тени является, вообще говоря, неоднородной: она выше вблизи края тени по сравнению с участками более далекими от края. Эту неоднородность следовало бы учитывать при моделировании влияния затенения на мощность ФМ. Однако, как показал эксперимент, значение пары величин $(I, V)$ вольтамперной характеристики определяется именно наименее освещенным участком в области тени. Поэтому при дальнейших расчетах мы считаем тень однородной, а интенсивность радиации в области тени равной минимальному значению на всем затененном поле модуля. Этот факт и отражен в формулах (1)-(3), в которых присутствует лишь одно значение $I_{\mathrm{s}}$, зависящее от относительной площади тени $s$.

Для получения зависимостей фактора $f(s)$ экспериментальные данные в виде пар значений $\left(P_{\mathrm{m}}, V_{\mathrm{m}}\right)$ для максимумов мощности интерполировались на весь интервал значений степени затенения $s$ с помощью полиномов Эрмита. На рисунке 5 приведены зависимости $f(s)$ (3) для фотомодулей SunRise SR 100W из моно-Si c портретной и фотомодулей Kvazar KV-100W из поли-Si с альбомной ориентацией, полученные на основании кривых $P(V)$ рисунков 26 и 2г. 

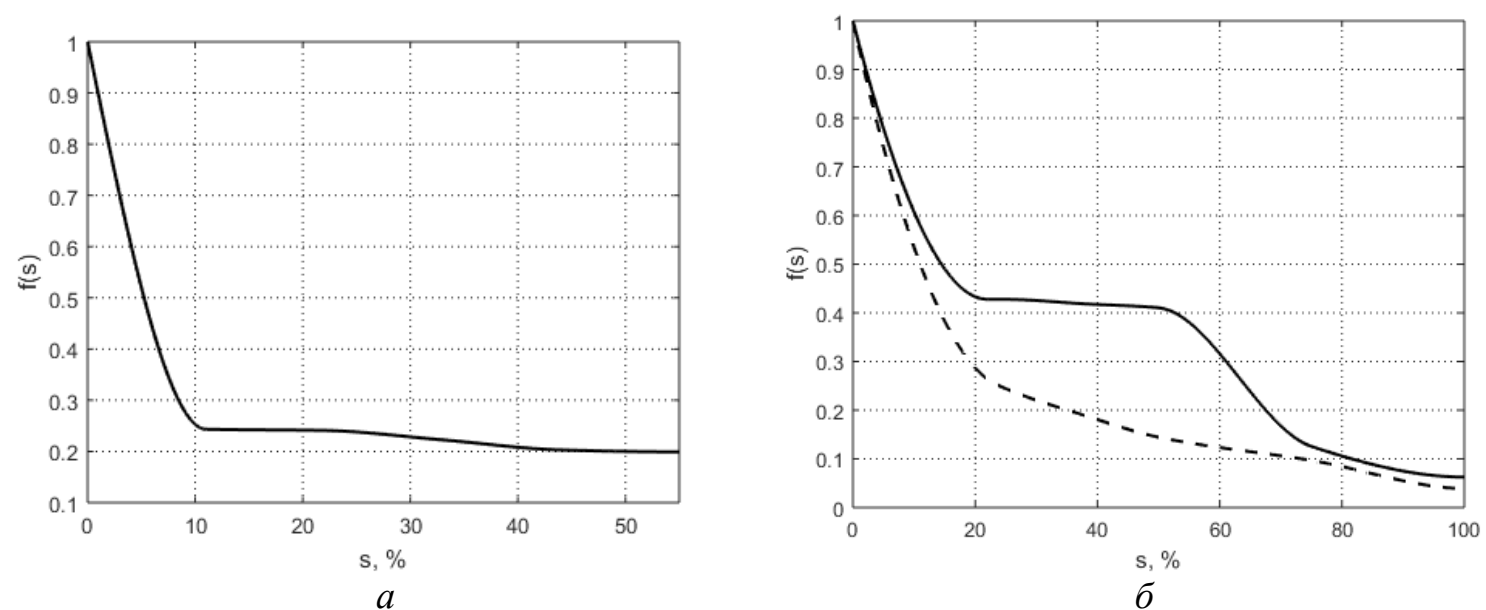

Рис. 5. Зависимости фактора потери мощности f(s) от относительной площади нижнего затенения: $a$ - портретная ориентация моно-Si ФМ; б - альбомная ориентация поли-Si ФМ; сплошная кривая относится к главному максимуму мощности, итриховая - к побочному максимуму.

Fig. 5. Dependences of the power loss factor $\mathbf{f}(\mathbf{s})$ on the relative area of the lower shading: $a$ - portrait orientation of mono-Si module; $b$-landscape orientation of poly-Si module; the solid curve refers to the main maximum of power, the dashed curve refers to the secondary maximum.

Из этих рисунков видно, что влияние степени затенения на выходную мощность системы ФМ имеет существенно нелинейный характер, а именно: величина фактора $f(s)$ на начальном участке кривой убывает непропорционально увеличению $s$. Связано это с тем, что при полном затенении нескольких ячеек модуля, ток протекает через обводной диод, и из процесса генерации исключается не только несколько затененных ячеек, но и все ячейки, шунтируемые диодом. Соответственно мощность модуля уменьшается на десятки процентов. При дальнейшем возрастании $s$ уменьшение тока генерации замедляется.

Исследования настоящей работы проводились в НТУУ «Киевский политехнический институт». Азимут нормали к поверхности исследованных фотомодулей был направлен на юг, а угол наклона модулей (угол между горизонтальной плоскостью и плоскостью ФМ) равнялся $35^{\circ}$. Этот угол наклона, как показано в следующем разделе статьи, является оптимальным для киевского региона.

5. Влияние фактора мощности на оптимальные межрядное расстояние и угол наклона солнечных панелей. На основе полученных зависимостей фактора мощности $f(s)$ от степени затенения можно выполнить вычисления выработки электроэнергии ФЭС с параллельным расположением рядов панелей ФМ, одинаково ориентированных по азимуту и имеющих определенный угол наклона $\beta$. При этом будем использовать подход [8], согласно которому для заданного географического места рассчитывается приход радиации на наклонную поверхность в течение календарного периода $T$ работы станции, определяется соответствующие число пиковых солнечных часов и выработка электроэнергии $E(T, \beta, \lambda)$ на единицу площади ФМ или единицу площади земельного участка в зависимости от двух параметров: угла наклона $\beta$ и плотности расположения рядов $\lambda=l / L$. Методика расчета позволяет построить поверхности $E(T, \beta, \lambda)$ и оптимизировать геометрические параметры системы фотомодулей ФЭС.

В качестве примера приведем результаты расчета $E(\beta, \lambda)$ для ФЭС, работающей в течение всего календарного года и установленной в Киевской области. При этом используем справочные радиационные данные для горизонтальной поверхности [22], полученные за продолжительный период времени. Фактор мощности $f(s)$ описываем интерполированными зависимостями, показанными на рисунках 5 а,б.

На рис. 6 приведены два типа контурных графиков $E(\beta, \lambda)$ при портретной ориентации ФМ: среднесуточная выработка на единицу площади панели (рис. 6а) и выработка на единицу площади земельного участка (рис. 6б). Используя первый тип графиков можно находить оптимальные $\lambda$ и $\beta$ для достижения максимальной выработки, приходящейся на единицу площади фотомодуля. Второй тип графиков следует использовать, когда стоит задача оптимизации $\lambda$ и $\beta$ для получения максимальной выработки с единицы площади земельного участка, на котором располагается ФЭС с одинаково ориентированными рядами солнечных панелей. 


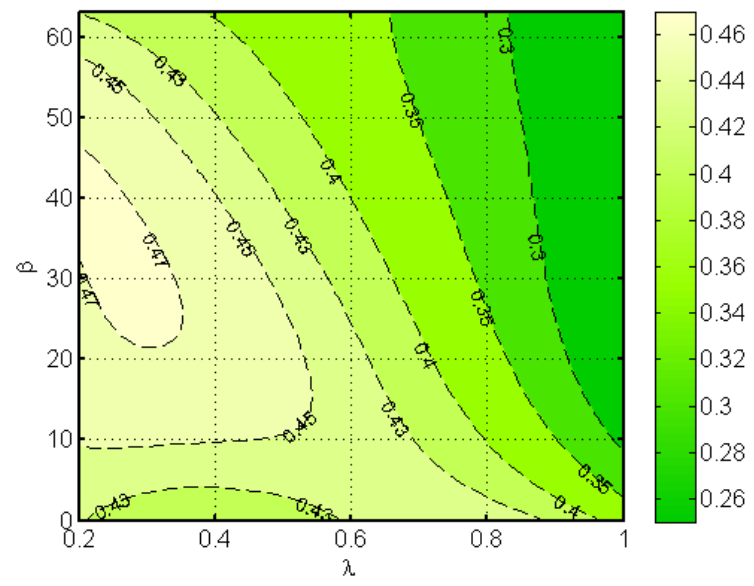

$a$

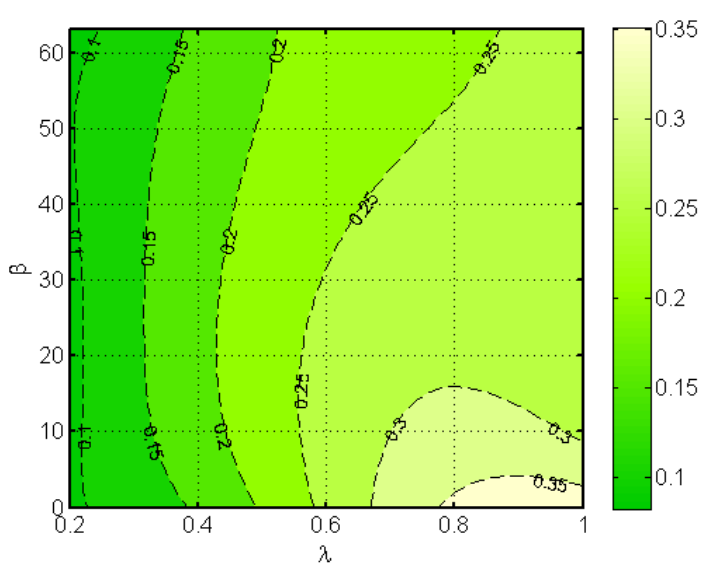

$\sigma$

Рис. 6. Контурные графики среднесуточной выработки ФЭС в районе Киева при портретной ориентации ФМ: $a-$ выработка энергии (кBm·ч) на $1 \mathcal{M}^{2}$ площуади ФМ; б - выработка энергии (кBm·ч) на $1 \mathrm{M}^{2}$ земельного участка.

Fig. 6. Contour graphs of the average daily output of PV systems in the Kiev region with a portrait orientation of the PV modules: $a$ - energy production $(k W \cdot h)$ per $1 \mathrm{~m} 2$ of the module area; $b$ - energy production $(k W \cdot h)$ per $1 \mathrm{~m} 2$ of land site.

Аналогичные графики для среднесуточной выработки, но при альбомной ориентации ФМ, т.е. при использовании фактора мощности для

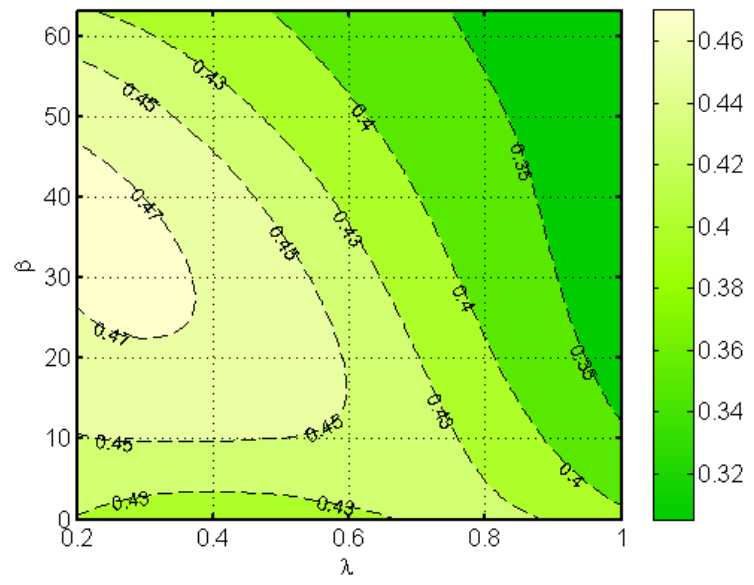

$a$ основного максимума мощности (см. рис. 5б), отслеживаемого с помощью инвертора, показаны на рис. 7.

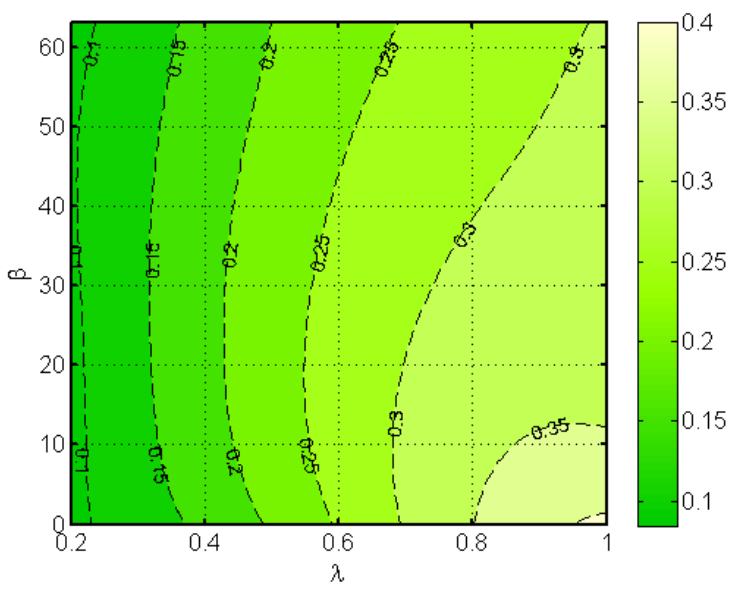

$\sigma$

Рис.7. Контурные графики среднесуточной выработки ФЭС в районе Киева при альбомной ориентации ФМ: $a-$ вblработка энергии (кBm·ч) на $1 \mathcal{M}^{2}$ площади ФМ; б-выработка энергии (кBm·ч) на $1 \mathcal{M}^{2}$ земельного участка.

Fig. 7. Contour graphs of the average daily output of PV system in the Kiev region with landscape orientation of PV modules: $a$ - energy production $(k W \cdot h)$ per $1 \mathrm{~m} 2$ of module area; $b$ - energy production $(k W \cdot h)$ per $1 \mathrm{~m} 2$ of land site.

Из графиков поверхностей $E(\beta, \lambda)$ рисунков 6а и 7а видно, что для рассмотренного региона максимальной выработки с единицы площади ФМ можно достичь при плотности рядов не превышающей 0.35 и угле наклона $(35 \pm 3)^{\circ}$ как для портретной, так и для альбомной ориентации модулей. Если же условием оптимизации является получение максимальной выработки с единицы площади земельного участка под ФЭС, то наибольшая выработка $\left(\sim 0.35 \mathrm{\kappa BT} \cdot 4 / 1 \mathrm{M}^{2}\right)$ при портретной ориентации панелей согласно графи- ку на рис.6б достигается при заполнении участка $\lambda=0.8-0.95$ и угле наклона панелей менее $3^{\circ}$. Альбомная ориентация допускает несколько большую выработку $\left(\sim 0.4 \quad\right.$ кВт.ч/1 $\left.\mathrm{M}^{2}\right)$ при $\lambda \geq 0.95$ и практически горизонтальном расположении ФМ (см. рис. 7б).

Зависимости среднесуточной выработки от плотности рядов для наглядности изобразим в виде двумерных графиков для альбомной (рис. 8) и портретной (рис. 9) ориентаций фотомодулей на ФЭС в районе Киева. 


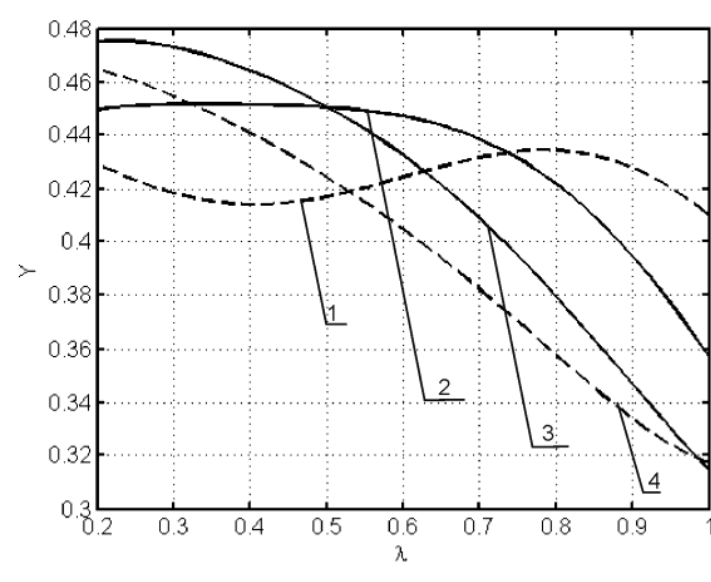

a

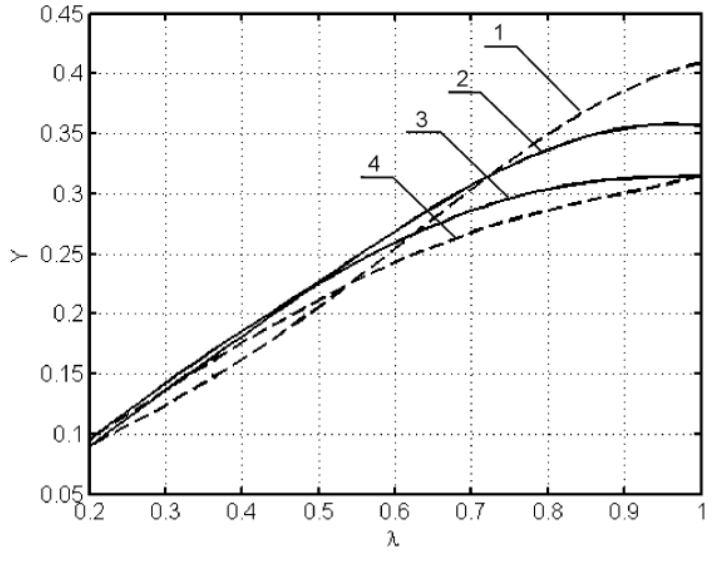

б

Рис. 8. Зависимости среднесуточной выработки от плотности рядов ФМ в альбомной ориентации при различных

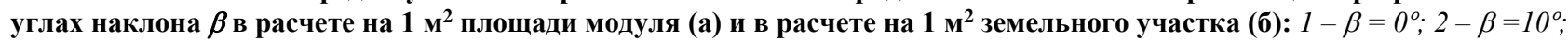
$3-\beta=35^{\circ} ; 4-\beta=50^{\circ}$.

Fig. 8. Dependences of the average daily output on the density of module rows in landscape orientation for various tilt angles $\beta$ and calculations per $1 \mathbf{m}^{2}$ of module area (a) and per $1 \mathbf{m}^{2}$ of land site (b): $1-\beta=0^{\circ} ; 2-\beta=10^{\circ}$; $3-\beta=35^{\circ} ; 4-\beta=50^{\circ}$.

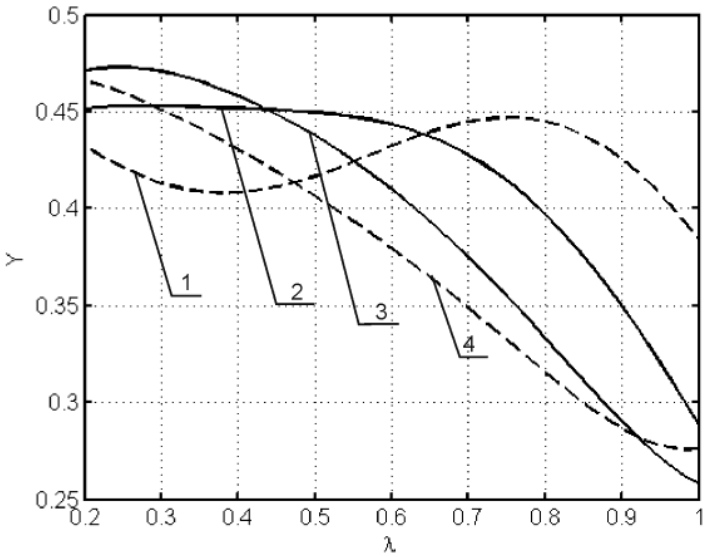

a

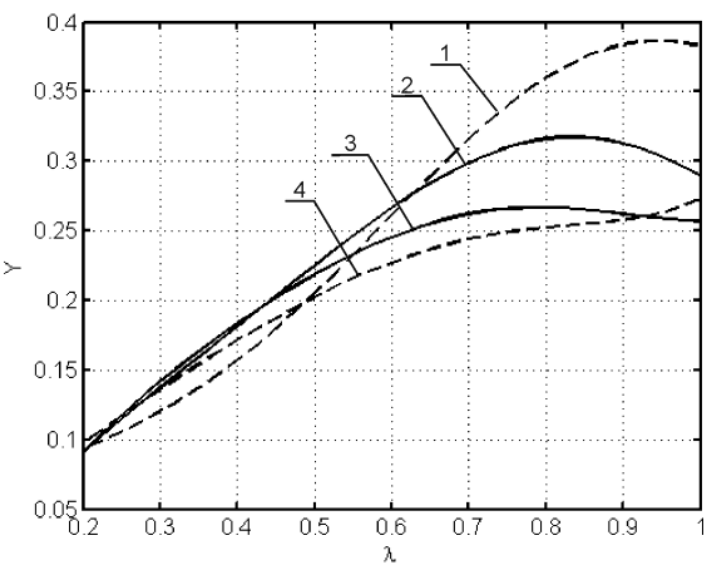

6

Рис. 9. Зависимости среднесуточной выработки от плотности рядов ФМ в портретной ориентации при различных

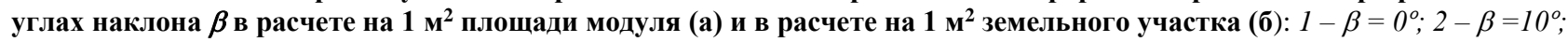
$3-\beta=35^{\circ} ; 4-\beta=50^{\circ}$.

Fig. 9. The dependences of the average daily output on the density of module rows in portrait orientation for various tilt angles $\beta$ and calculations per $1 \mathbf{m}^{2}$ of module area (a) and per $1 \mathbf{m}^{2}$ of land site (b): $1-\beta=0^{\circ} ; 2-\beta=10^{\circ}$; $3-\beta=35^{\circ} ; 4-\beta=50^{\circ}$.

На графиках рисунков 8, 9 изображены сечения поверхностей $E(\beta, \lambda)$ при фиксированных углах $\beta$. Наибольшая выработка в расчете на $1 \mathrm{~m}^{2}$ площади модуля при обоих видах ориентации достигается, когда плотность рядов составляет менее 0.3 , а угол наклона равен оптимальному значению $35^{\circ}$ для изолированных панелей. Для получения максимальной выработки с $1 \mathrm{~m}^{2}$ земельного участка оптимальным является горизонтальное по- ложение панелей $\left(\beta=0^{\circ}\right)$ и максимально плотное расположение рядов $(\lambda>0.95)$. Если же выбран оптимальный угол наклона $\beta=35^{\circ}$ (как для изолированных панелей), то недобор среднесуточной выработки при плотности, например, $\sim 0.75$ составит порядка $30 \%$ по сравнению с горизонтальным расположением панелей (см. рис. 8б, 9б).

Результаты и выводы. 1. В настоящей работе с помощью созданной измерительной уста- 
новки на базе микропроцессора Atmel 328 проведены измерения ВАХ фотомодулей из моно- и поликристаллического кремния в условиях различной степени частичного затенения. Были исследованы горизонтальное (альбомное) и вертикальное (портретное) расположения модулей, которые при нижнем частичном затенении модулей приводят к различию в вольтамперных характеристиках и кривых мощности.

2. Показано, что выработку ФЭС с учетом частичного затенения можно с достаточной степенью точности вычислить, если ввести фактор мощности $f(s)$ модулей, зависящий от степени затенения $s$, который определяеться на основе экспериментально полученных ВАХ. Разработан метод вычисления генерации ФЭС за определенный календарный период на основе рассчитанной функции $f(s)$ и метеорологических данных по среднемесячным суммам радиации.

3. Анализ построенных моделей генерации и потери мощности при частичном затенении удобно разделить на две части соответственно двум типам задач: обеспечение максимума выработки на единицу площади фотомодулей и на единицу площади земельного участка. В работе построены карты распределения среднесуточной генерации $E(\beta, \lambda)$ для указанных двух типов оптимизационных задач.

4. Численные расчеты по поиску максимума генерации в задачах первого типа показал следующее. Максимальная выработка с единицы площади ФМ обеспечивается согласно расчетам с использованием функции $f(s)$ для Киева и области при $\lambda \leq 0.35, \beta \approx 30^{\circ}$. Это относится как к альбомной, так и к портретной ориентации ФМ. Расчет выработки в задачах второго типа показал, что максимальная выработка с единицы площади земельного участка достигается при наиболее полном заполнении участка, когда $\lambda \geq 0.95$ и угол наклона менее $1^{\circ}$ как при портретной, так и при альбомной ориентации ФМ. Отметим, что относительная погрешность вычислений, выполненных в пакете MATLAB, coставляет не более $1 \%$ (с учетом процедур аппроксимации и интерполяции).

5. Полученные на основе оптимизационных расчетов численные результаты и графики позволяют судить о тенденциях изменения эффективности больших ФЭС в зависимости от конструкционных параметров рядов солнечных панелей и ориентации ФМ. Развитый в настоящей работе метод обработки измерений $\mathrm{BAX}$ фотомодулей при различном затенении и аналитический расчет среднесуточной выработки позволяет найти ин- тервалы оптимальных значений углов наклона и межрядных расстояний солнечных панелей для конкретных регионов расположения ФЭС.

1. Chang T.P. Study on the optimal tilt angle of solar collector according to different radiation types. Int. Journ. of Applied Science and Engineering. 2008. V.6. Pp. 151-161.

2. Mehleri E.D., Zervas P.L. et al. Determination of the optimal tilt angle and orientation for solar photovoltaic arrays. Renew. Energy. 2010. V. 35. Pp. 2468- 2475.

3. Гаевский А.Ю., Гаевская А.Н. Метод определения оптимального угла наклона и ориентации фотоэлектрических модулей на основе экспериментальных данных солнечной радиации. Альтернативная энергетика и экология. 2018. № 13-15. С. 15-29.

4. Rauschenbach H.S. Electrical output of shadowed solar arrays. IEEE Trans. Electron Dev. 1971. V. 1. No. 8. URL: http://dx.doi.org/ .

5. Deline C. A simplified model of uniform shading in large photovoltaic arrays. Solar Energy. 2013. V. 96. Pp. 274-282.

6. Гаєвський О.Ю., Врещ М.О., Мельник О.В. Аналіз ефекту затінення фотоелектричних модулів у послідовнопаралельному з'єднанні. Відновлювана енергетика. 2013. № 1 . C. $28-30$.

7. Abdullah Al Mamun M. Experimental investigation of the effect of partial shading on photovoltaic performance. IET Renewable Power Generation. 2017. V. 11. No. 7. Pp. 912-921.

8. Гаевский А.Ю., Демин Д.А. Влияние угла наклона и плотности расположения фотомодулей на эффективность ФЭС. Альтернативная энергетика и экология. 2018. № 25-27. C. $273-275$.

9. Erge Th., Hoffmann V.U. The German 1000-roofsPV-programme - a resume of the 5 years pioneer project for small grid-connected PV systems. Proceedings of the 2nd World Conference on PVSEC. Vienna. 1998. Pp. 2648-2651.

10. Kurokawa $K$. Realistic values of various parameters for PV system design. Renewable Energy. 1998. V.15. Pp. 157-164.

11. Woyte A., Nijs J., Belmans R. Partial shadowing of photovoltaic arrays with different system configurations: literature review and field test results. Solar Energy. 2003. V. 74. Pp. 217-233.

12. Bashahu M., Nkundabakura P. Review and tests of methods for the determination of the solar cell junction ideality factor. Solar Energy. 2007. V. 81. Pp. 856-863.

13. Humada A.M. Solar cell parameters extraction based on single and double-diode models. A review. Renewable and Sustainable Energy Reviews. 2016. V. 56. Pp. 494-509.

14. Ma J., Man K. Approximate Single-Diode Photovoltaic Model for Efficient I-V Characteristics Estimation. The Scientific World Journal. Vol. 2013. 7 p. Article ID 230471.

15. Zhang C., Zhang J., Hao $Y$. et al. A simple and efficient solar cell parameter extraction method from a single current-voltage curve. Journal of Applied Physics. 2011. V. 110, $064504.7 \mathrm{p}$.

16. Гаевский А.Ю. Определение параметров фотоэлектрических модулей на основе точного решения уравнения для ВАХ. Відновлювана енергетика. 2012. № 4. С.32-39.

17. Kong K.C., Mamat M., Ibrahim M.Z. New Approach on Mathematical Modeling of Photovoltaic Solar Panel. Applied Mathematical Sciences. 2012. V. 6. Pp. 381-401.

18. Karatepe E., Boztepe M., Colak M. et al. Development of a suitable model for characterizing photovoltaic arrays with shaded solar cells. Solar Energy. 2007. V. 81. Pp. 977-992.

19. Гаевская А.Н. Алгоритм аппроксимации вольтамперной характеристики фотомодуля в условиях затенения. Відновлювана енергетика. 2019. №3. С. 21-29. 
20. Bashahu M., Nkundabakura P. Review and tests of methods for the determination of the solar cell junction ideality factors. Solar Energy. 2007. V. 81. № 7. Pp.856-863.

21. Gaevskii A. Method for determining parameters of PV modules in field conditions. 2019 IEEE 6th International Conference on Energy Smart Systems. April 17-19. 2019. Kyiv. Ukraine. DOI: 10.1109/ESS.2019.8764239.

22. Справочник по климату СССР. Украинская ССР Часть I. Солнечная радиация, радиационный баланс и солнечное сияние. Ленинград.Гидрометеорологическое изд 1966. $126 \mathrm{c}$

\section{REFERENCES}

1. Chang T.P. Study on the optimal tilt angle of solar collector according to different radiation types. Int. Journ. of Applied Science and Engineering. 2008. V.6. Pp. 151-161. [in English].

2. Mehleri E.D., Zervas P.L. et al. Determination of the optimal tilt angle and orientation for solar photovoltaic arrays. Renew. Energy. 2010. V. 35. Pp. 2468- 2475. [in English].

3. Gaevskiy A.Yu., Gaevskaya A.N. Metod opredeleniya optimalnogo ugla naklona i orientatsii fotoelektricheskih moduley na osnove eksperimentalnyih dannyih solnechnoy radiatsii. [Method for determina-tion of the optimal PV modules tilt and azimuth angles on the base of solar irradiation data] Alternativnaya energetika i ekologiya. 2018. No. 13-15. Pp.1529. [in Russian].

4. Rauschenbach H.S. Electrical output of shadowed solar arrays. IEEE Trans. Electron Dev. 1971. V. 1. No. 8. URL: http://dx.doi.org/ . [in English].

5. Deline $C$. A simplified model of uniform shading in large photovoltaic arrays. Solar Energy. 2013. V. 96. Pp. 274-282.

6. Gayevskii O.Yu., Vreshch M.O., Melnyk O.V. Analiz efektu zatinennia fotoelektrychnykh moduliv u poslidovnoparalelnomu ziednanni. [Analysis of the PV modules shading effect in series-parallel connections]. Vidnovluvana energetika. 2013. No. 1. Pp. 28-30. [in Ukrainian].

7. Abdullah Al Mamun M. Experimental investigation of the effect of partial shading on photovoltaic performance. IET Renew-able Power Generation. 2017. V. 11. No. 7. Pp. 912-921. [in English].

8. Gaevskiy A.Yu., Demin D.A. Vliyanie ugla naklona i plotnosti raspolozheniya fotomoduley na effektivnost FES [Impact of the tilt angle and solar panels row spacing on PV plant yield]. Alternativnaya energetika i ekologiya. 2018. No. 25-27. Pp. 273-275. [in Russian].

9. Erge Th., Hoffmann V.U. The German 1000-roofs-PVprogramme - a resume of the 5 years pioneer project for small grid-connected PV systems. Proceedings of the 2nd World Conference on PVSEC. Vienna. 1998. Pp. 2648-2651. [in English].

10. Kurokawa $K$. Realistic values of various parameters for PV system design. Renewable Energy. 1998. V.15. Pp. 157164. [in English].

11. Woyte A., Nijs J., Belmans R. Partial shadowing of photovoltaic arrays with different system configurations: literature review and field test results. Solar Energy. 2003. V. 74. Pp. 217-233. [in English].

12. Bashahu M., Nkundabakura P. Review and tests of methods for the determination of the solar cell junction ideality factor. Solar Energy. 2007. V. 81. Pp. 856-863. [in English].

13. Humada A.M. Solar cell parameters extraction based on single and double-diode models. A review. Renewable and Sustainable Energy Reviews. 2016. V. 56. Pp. 494-509. [in English].

14. Ma J., Man K. Approximate Single-Diode Photovoltaic Model for Efficient I-V Characteristics Estimation. The Scientific World Journal. Vol. 2013. 7 p. Article ID 230471. [in English].
15. Zhang C., Zhang J., Hao $Y$. et al. A simple and efficient solar cell parameter extraction method from a single current-voltage curve. Journal of Applied Physics. 2011. V. 110, 064504. 7 p. [in English].

16. Gaevskiy A.Yu. Opredelenie parametrov fotoelektricheskih moduley na osnove tochnogo resh-eniya uravneniya dlya VAH. [Determina-tion of PV module parameters based on exact solution of the CVC equation]. Vidnovluvana energetika. 2012. No. 4. Pp.32-39. [in Russian].

17. Kong K.C., Mamat M., Ibrahim M.Z. New Approach on Mathematical Modeling of Photovoltaic Solar Panel. Applied Mathematical Sciences. 2012. V. 6. Pp. 381-401. [in English].

18. Karatepe E., Boztepe M., Colak M. et al. Development of a suitable model for characterizing photovoltaic arrays with shaded solar cells. Solar Energy. 2007. V. 81. Pp. 977-992. [in English].

19. Gaevskaya A.N. Algoritm approksimatsii voltampernoy harakteristiki fotomodulya $\mathrm{v}$ usloviyah zateneniya. [Approximation of volt-ampere characteristics of PV module obtained under shading conditions]. Vidnovluvana energetika. 2019. No. 3. Pp. 21-29. [in Russian].

20. Bashahu M., Nkundabakura P. Review and tests of methods for the determination of the solar cell junction ideality factors. Solar Energy. 2007. V. 81. № 7. Pp.856-863. [in English].

21. Gaevskii A. Method for determining parameters of PV modules in field conditions. 2019 IEEE 6th International Conference on Energy Smart Systems. April 17-19. 2019. Kyiv. Ukraine. DOI: 10.1109/ESS.2019.8764239. [in English]

22. Spravochnik po klimatu SSSR. Ukrainskaya SSR. Chast I. Solnechnaya radiatsiya, radi-atsionnyiy balans i solnechnoe siyanie. [Reference book on USSR climate. Ukrainian SSR. Part I. Solar irradiation, radiation balance and sunshine]. Leningrad. Gidrometeorologicheskoe izd. 1966. 126 p. [in Russian].

\section{ФАКТОР ВТРАТИ ПОТУЖНОСТІ ФОТОЕЛЕКТРИЧНИХ МОДУЛІВ ПРИ ЇХ ВЗАСМНОМУ ЗАТІНЕННI \\ ТА ОПТИМІЗАЦІЯ КУТІВ НАХИЛУ І ВІДСТАНЕЙ МІж РЯДАМИ МОДУЛІВ}

\section{Д.А. Дьомін ${ }^{1,2}$, А.Н. Гасвська ${ }^{1}$, А.Ю. Гаєвський ${ }^{1,2}$}

${ }^{1}$ Національний технічний університет України «Київський політехнічний інститут ім. Ігоря Сікорського», 03056, пр-т. Перемоги, 37 , м. Київ, Україна.

2 Інститут відновлюваної енергетики НАН України, 02094, вул. Гната Хоткевича, 20А, м. Київ, Україна.

Істотним чинником, що впливає на середньодобовий виробіток електроенергії фотоелектричними станціями (ФЕС), $\epsilon$ взаємне затінення сусідніми рядами фотомодулів (ФМ). Для зменшення ступеня впливу взаємного затінення на виробіток ФЕС необхідне рішення задачі оптимізації міжрядних відстаней $і$ висоти рядів ФМ, тобто їх кутів нахилу. Незважаючи на геометричний характер иій задачі, іï рiшення не є тривіальним, оскільки потрібно враховувати зміни кута висоти сонця, зміни інтенсивності радіації на похилій поверхні, а також варіачії співвідношення прямої та дифузійної компонент радіачії протягом світлового дня $i$ протягом всього календарного періоду роботи ФЕС. У даній роботі для опису ступеня впливу часткового затінення на вихідну потужність рядів ФМ введений фактор ослаблення їх потужності при затіненні. Цей фактор визначений на основі експериментальних вольтамперних характеристик (ВАХ), знятих на розробленої нами установиі для польових вимірювань ВАХ в умовах нижнього затінення $у$ випадках горизонтального і вертикального розтамування 
модулів. Отримані залежності фактора потужності ФМ від ступеня затінення використані для обчислення запропонованих нами карт середньодобового виробітку фотоелектричної системи в координатах «щільність розміщення рядів - кут нахилу». Вихідними даними, крім фактора ослаблення потужності, є погодинні суми прямої та дифузійної радіачї на горизонтальну по-поверхню для кожного місяия періоду роботи ФЕС. Розроблений метод дозволяє знайти оптимальні конфігураиії рядів ФМ при виріменні двох типів оптимізачійних задач: (1) забезпечення максимального виробітку при заданій установчої потужності ФЕС $i$ (2) отримання максимального виробітку з одиниці площі земельної ділянки. Метод може бути застосований для будьякого сезонного періоду роботи ФЕС $і$ будь-якого регіону, для якого є зазначені вище радіачійні дані.

Ключові слова: фотоелектричні станції, взаємне затінення рядів фотомодулів, оптимізачія кута нахилу, оптимізація межрядніх відстаней, виробіток електроенергї.

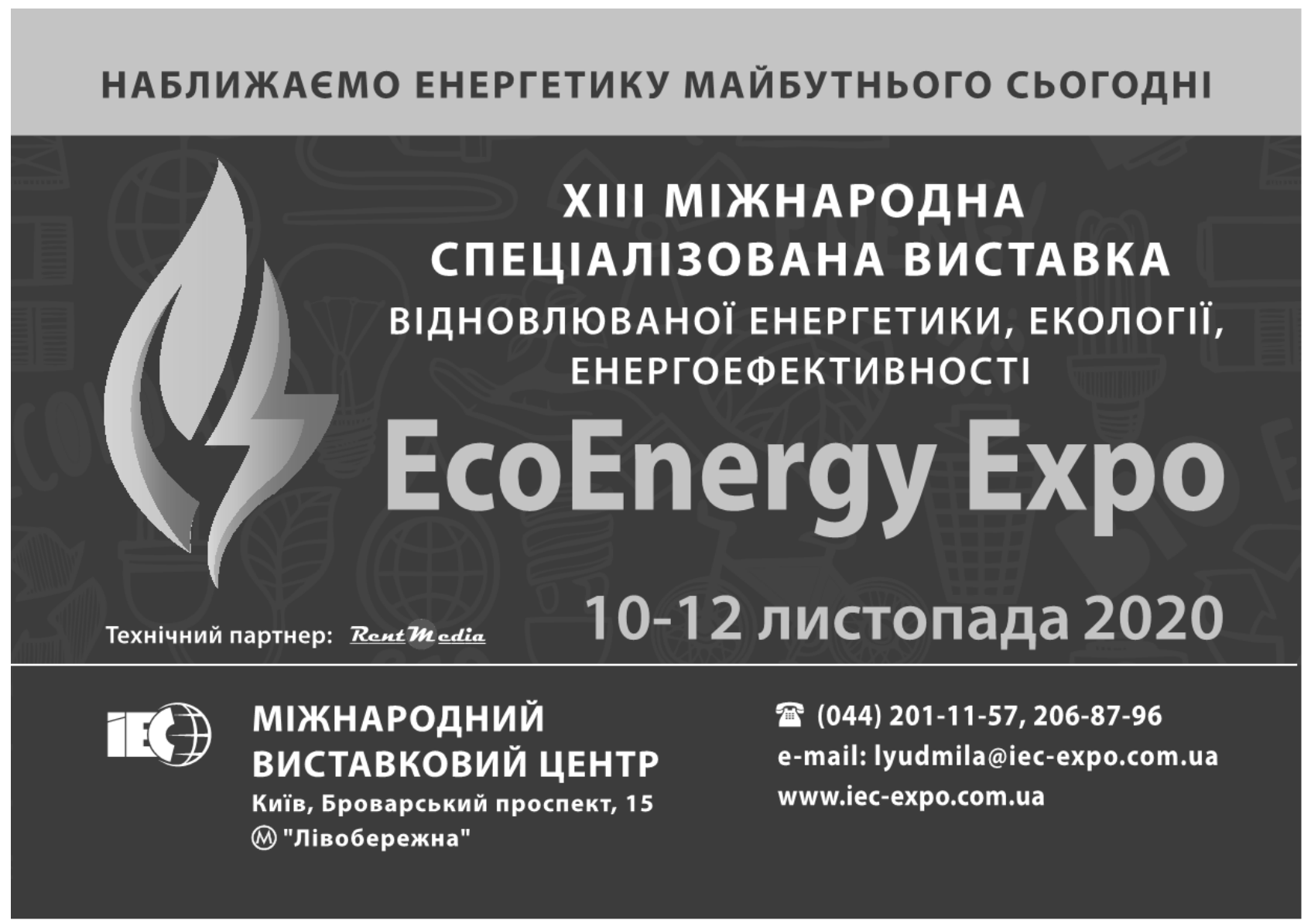

